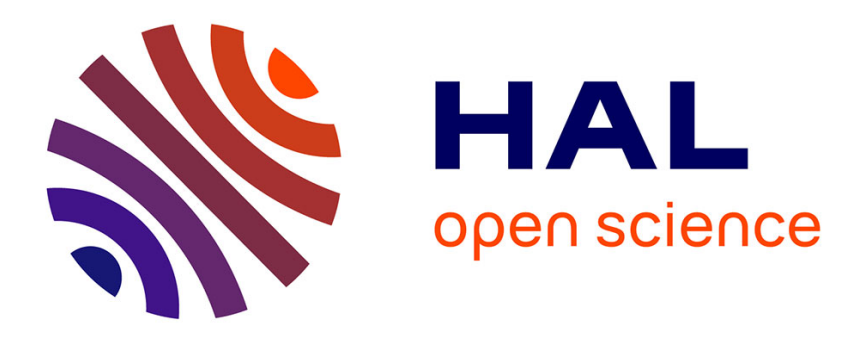

\title{
MODELING LANTHANIDE BINDING SITES ON HUMIC ACID
}

Olivier Pourret, Raul E. Martinez

\section{To cite this version:}

Olivier Pourret, Raul E. Martinez. MODELING LANTHANIDE BINDING SITES ON HUMIC ACID. Journal of Colloid and Interface Science, 2009, 330, pp.45-50. 10.1016/j.jcis.2008.10.048 . hal-00430267

\section{HAL Id: hal-00430267 https://hal.science/hal-00430267}

Submitted on 6 Nov 2009

HAL is a multi-disciplinary open access archive for the deposit and dissemination of scientific research documents, whether they are published or not. The documents may come from teaching and research institutions in France or abroad, or from public or private research centers.
L'archive ouverte pluridisciplinaire HAL, est destinée au dépôt et à la diffusion de documents scientifiques de niveau recherche, publiés ou non, émanant des établissements d'enseignement et de recherche français ou étrangers, des laboratoires publics ou privés. 


\section{MODELLING LANTHANIDE SERIES BINDING SITES ON}

\section{HUMIC ACID}

Olivier Pourret ${ }^{1, *}$ and Raul E. Martinez ${ }^{2, \#}$

${ }^{1}$ Institut Polytechnique LaSalle-Beauvais, Département Géosciences, 19 rue Pierre Waguet, 60026 Beauvais Cedex, France

${ }^{2}$ Institut de Physique du Globe de Paris, Laboratoire Géobiosphère Actuelle et Primitive, 4 place Jussieu, 75252 Paris Cedex 05, France

Keywords: Rare earth elements, humic acid, binding, speciation, LPM model

*Corresponding author: Tel.: +33 344068 979; Fax: + 33344068 970. E-mail address: olivier.pourret@lasallebeauvais.fr.

\#Present address: Tübingen University, Institute for Geoscience, Hölderlinstr. 16, 72074 Tübingen, Germany 


\begin{abstract}
Lanthanide (Ln) binding to humic acid (HA) has been investigated by combining ultrafiltration and ICP-MS techniques. A Langmuir sorption isotherm metal complexation model was used in conjunction with a linear programming method (LPM) to fit experimental data representing various experimental conditions both in HA/Ln ratio (varying between 5 and 20) and in $\mathrm{pH}$ range (from 2 to 10 ) with a ionic strength of $10^{-3} \mathrm{~mol} \mathrm{~L}^{-1}$. The LPM approach, not requiring prior knowledge of surface complexation parameters, was used to solve the existing discrepancies in LnHA binding constants and site densities. The application of the LPM to experimental data revealed the presence of two discrete metal binding sites at low humic acid concentrations, (5 mg L $\left.{ }^{-1}\right)$, with log metal complexation constants (log $\left.K_{\mathrm{S}, \mathrm{j}}\right)$ of $2.65 \pm 0.05$ and 7.00 (depending on Ln). The corresponding site densities were $2.71 \pm 0.57 \times 10^{-8}$ and $0.58 \pm 0.32$ x $10^{-8}$ moles of $\mathrm{Ln}^{3+} / \mathrm{mg}$ of HA (depending on Ln). Total site densities of $3.28 \pm 0.28 \times 10^{-8} \mathrm{~mol}$ $\mathrm{mg}^{-1}, 4.99 \pm 0.02 \times 10^{-8} \mathrm{~mol} \mathrm{mg}^{-1}$ and $5.01 \pm 0.01 \times 10^{-8} \mathrm{~mol} \mathrm{mg}^{-1}$ were obtained by LPM for humic acid, for HA concentration of $5 \mathrm{mg} \mathrm{L}^{-1}, 10 \mathrm{mg} \mathrm{L}^{-1}$ and $20 \mathrm{mg} \mathrm{L}^{-1}$, respectively. These results confirm that lanthanide binding occurs mainly at weak sites (i.e., ca. 80\%) and secondly at strong sites (i.e., ca. 20\%). The first group of discrete metal binding sites may be attributed to carboxylic groups (known to be the main binding sites of Ln in HA), and the second metal binding group to phenolic moieties. Moreover, this study evidences heterogeneity in the distribution of the binding sites among Ln. Eventually, the LPM approach produced feasible and reasonable results, but it was less sensitive to error and did not require an a priori assumption of the number and concentration of binding sites.
\end{abstract}




\section{INTRODUCTION}

The solution and mineral properties of lanthanides ( $\mathrm{Ln})$ make these trace elements excellent probes of low temperature geochemical reactions. Interest in Ln geochemistry comes from their systematic in chemical properties that often leads to fractionation in geochemical systems [1]. Ln form a coherent geochemical group of trace elements that generally occur in the trivalent oxidation state. The effective ionic radii of Ln systematically decrease when atomic number increases [2] producing characteristic regular features of normalised Ln patterns defining the CHArge and RAdius-Controlled process, CHARAC [3]. If a low temperature geochemical system is characterized by CHARAC behaviour, elements of similar charge and radius such as Ln are, should display extremely coherent behaviour. This behaviour disappears when chemical processes are mainly driven by electronic external configuration producing sub-partition (nonCHARAC processes). CHARAC behaviour of Ln should thus generate smooth patterns whereas irregular patterns (excepting redox-related anomalies) may indicate non-CHARAC behaviour. By studying fractionation trends, it then becomes possible to quantify the underlying fractionation processes in the natural environment (e.g., [3, 4]). In addition, quantification of Ln fractionation in natural geochemical systems is essential for the modelling of the immobilization and transport of radioactive elements, as Ln are often used as naturally occurring analogs for the trivalent actinides [5].

In aquatic geochemical systems Ln fractionation occcurs by complexation to organic or inorganic ligands, or adsorption onto aquifer minerals. In natural waters, Ln may be associated with organic colloids which play a key role in complexing Ln elements and facilitate the fractionation of the Ln series (e.g., [6-10]). Dissolved organic matter (DOM), including humic acids (HA) and fulvic acids (FA), are abundant in surface water and groundwater systems [11]. HA are potent sorbents of dissolved metal cations like Ln elements (e.g., [10]). These properties emphasize the importance of HA in regulating the speciation, transport and subsequent 
fractionation of Ln in pristine and contaminated aquatic environments. The physicochemical quantification of Ln interaction with DOM in aquatic systems is needed to predict Ln fractionation by organic metal complexation in aqueous systems. HA contains an important number of potential metal complexing functional groups including carboxylic sites (e.g., [12]). Their chemical arrangement and conformation at the molecular level affects the ability of HA to complex Ln elements. For this reason, surface complexation modelling of LnHA acid interactions, using current surface complexation models such as FITEQL [13], WHAM and Model V and VI [14], or NICA Donnan [15] may provide different discrete metal binding constants for similar LnHA complexation reactions. Few studies have addressed LnHA interactions as a function of $\mathrm{pH}$, ionic strength and different Ln elements. Only a small number of single Ln complexation constants with HA (SmHA, EuHA, TbHA and DyHA) have been evaluated [16-21]. Results from recent studies suggest that most of the LnHA complexation constants have to be measured or interpolated, especially for the whole Ln series [22], [23]. In these studies LnHA interactions have been investigated using binding interactions which are based on one- and two-site conditional binding to discretized multi-site (e.g., [24]), and continuous distribution models (e.g., [15]). Various electrostatic models have been developed to account for $\mathrm{pH}$ and $I$ effects ion binding (e.g., [24]). Sonke and Salters [25] adopted a monodentate (carboxylic) binding mechanism. The exact binding site nature, multi-dentism, and polyelectrolyte effects of HA are ignored in the monodentate binding concept and therefore implicitly included in the conditional binding constant, which consequently is only valid for a specific pH, I, and temperature. Sonke [26], Pourret et al. [27] and Stern et al. [28] further investigated this feature using Model V and VI. However, such modelling of LnHA complexation only considers specific constants and thus does not implicitly distinguish different binding sites.

The effects of HA on Ln fractionation was previously studied by monitoring the concentration of Ln as a function of increasing concentrations of HA [27]. The resultant sorption 
data were analyzed to assess multi-site metal surface binding using linear programming regression methods (LPM) [29-31]. Most previous studies have investigated HA surface interactions with metals using single-site sorption isotherms that do not adequately describe the heterogeneity of HA surfaces [32]. Despite the previous application of LPM to describe metal binding to organic surfaces [29-31], this modelling approach has not yet been applied to study LnHA interactions.

\section{MODELLING OF LnHA COMPLEXATION DATA}

The experimental data used in this study has been previously published by Pourret et al. [27]. Ln complexation with HA was investigated using a standard batch equilibration technique. Ln (ranging from 360 to $286 \mathrm{nmol} \mathrm{L}^{-1}$ depending on Ln) and Aldrich HA (5, 10 and $20 \mathrm{mg} \mathrm{L}^{-1}$ ) were placed together in solution, at an ionic strength of $1 \times 10^{-3} \mathrm{~mol} \mathrm{~L}^{-1}$ and at $\mathrm{pH}$ values ranging from 2.18 to 10.44 . The present work will model Ln complexation to HA data using a surface complexation modelling approach, the LPM method as described previously by Martinez and Ferris [30] and Martinez et al. [31], which does not require prior knowledge of log $K$ or binding site concentrations. In order to describe $\mathrm{Ln}^{3+}$ complexation to deprotonated HA sites, $\mathrm{HA}^{-}$, a competition reaction was assumed to take place in a 1:1 ratio, as follows:

$$
\mathrm{HHA}_{\mathrm{j}}+\mathrm{Ln}^{3+} \leftrightharpoons \mathrm{LnHA}_{\mathrm{j}}^{2+}+\mathrm{H}^{+}
$$

where $\mathrm{HHA}_{\mathrm{j}}$ represents $\mathrm{HA}$ reactive site. $\mathrm{K}_{\mathrm{S}, \mathrm{j}}$ represents the concentration apparent equilibrium

constant for the reaction in Equation 1, conditional on ionic strength. For a $j^{\text {th }}$ deprotonated binding site at the $i^{\text {th }}$ step of the titration, $\mathrm{K}_{\mathrm{S}, \mathrm{j}}$ can be defined as: 


$$
K_{S, j}=\frac{\left[\operatorname{LnH} A_{j}^{2+}\right]_{i} \cdot\left[H^{+}\right]_{\text {meas }, i}}{\left[H A_{j}\right]_{i} \cdot\left[\operatorname{Ln}_{S}^{3+}\right]_{\text {meas }, i}}
$$

where $i=1, \ldots, n$ titrant additions and $j=1, \ldots, m$ binding sites. In the above expression, $K_{\mathrm{S}, j}$ implicitly embodies electrostatic parameters and is a function of experimentally determined proton and metal concentrations, $\left(\left[\mathrm{H}^{+}\right]_{\text {meas }, i}\right.$ and $\left.\left[\mathrm{Ln}^{3+}\right]_{\text {meas }, i}\right)$ and of the amount of $\mathrm{Ln}^{3+}$ bound to the $j^{\text {th }}$ site at the $i^{\text {th }}$ step of the titration, $\left[\operatorname{LnHA}_{j}^{2+}\right]_{i}$. The total bound metal at the $i^{\text {th }}$ titrant addition, $\left[\mathrm{LnHA}^{2+}\right]_{\mathrm{T}, i}$, and the total ligand concentration, $[\mathrm{HA}]_{\mathrm{T}}$, can be expressed as:

$$
\left[\operatorname{LnHA}^{2+}\right]_{T, i}=\sum_{j=1}^{m}\left[\operatorname{LnHA}_{j}^{2+}\right]_{i}=\left[\operatorname{Ln}^{3+}\right]_{T}-\left[\operatorname{Ln}^{3+}\right]_{\text {neas }, i}
$$

and

$$
[H A]_{T}=\sum_{j=1}^{m}\left[H A_{j}\right]=\left[L n H A_{j}^{2+}\right]+\left[H A_{j}^{-}\right]+\left[H H A_{j}\right]
$$

where $\left[\mathrm{HA}_{\mathrm{j}}^{-}\right]$refers to the individual site density for a particular surface functional group type. The total concentration of bound metal, $\left[\mathrm{LnHA}^{2+}\right]_{\mathrm{T}, i}$, can be expressed as a sum of complexed metal concentrations for each of the $j^{\text {th }}$ surface ligands at the $i^{\text {th }}$ step of the titration. However, experimental measurements of total, $\left[\mathrm{Ln}^{3+}\right]_{\mathrm{T}}$, and free metal concentrations $\left[\mathrm{Ln}^{3+}\right]_{\text {meas }, i}$, only allow direct determination of $\left[\mathrm{LnHA}^{2+}\right]_{\mathrm{T}, i}$, as indicated by Equation 3 .

The fraction of the total $j^{\text {th }}$ ligand concentration, bound by $\mathrm{Ln}^{3+}$ at the $i^{\text {th }}$ step of the titration, $\alpha_{\mathrm{LnHA}, i j}$, can be expressed as a function of the bound metal (i.e., $\mathrm{Ln}^{3+}$ ) at the $i^{\text {th }}$ titrant addition, $\left[\mathrm{LnHA}^{2+}{ }_{\mathrm{j}}\right]_{i}$ and the $j^{\text {th }}$ ligand concentration, $\left[\mathrm{HA}_{\mathrm{j}}^{-}\right]$as follows: 


$$
\alpha_{L n H A, i j}=\frac{\left[L n H A_{j}^{2+}\right]_{i}}{\left[H A_{j}^{-}\right]}=\frac{\left[L n H A_{j}^{2+}\right]_{i}}{\left[L n H A_{j}^{2+}\right]_{i}+\left[H H A_{j}\right]_{i}}
$$

The protonated $j^{\text {th }}$ ligand concentration at the $i^{\text {th }}$ step of the titration, $\left[\mathrm{HHA}_{\mathrm{j}}\right]_{i}$, can in turn be expressed as a function of $\left[\mathrm{LnHA}^{2+}\right]_{i}$, by rearranging the expression for the equilibrium constant $K_{\mathrm{S}, j}$ in Equation 2. The calculated bound metal concentration at the $i^{\text {th }}$ titrant addition, $\left[\mathrm{LnHA}^{2+}\right]_{\mathrm{T}, \text { calc }, i}$, can then be determined as a function of measured, $\left(\left[\mathrm{H}^{+}\right]_{\text {meas }, i}\right.$ and $\left.\left[\mathrm{Ln}^{3+}\right]_{\text {meas }, i}\right)$ and adjustable $\left(\left[\mathrm{HA}_{\mathrm{j}}^{-}\right]\right)$parameters, as shown below:

$$
\left[\operatorname{LnHA}^{2+}\right]_{T, \text { calc }, i}=\sum_{j=1}^{m}\left(\alpha_{\text {LnHA,ij }}\left[H A_{j}^{-}\right]\right)=\sum_{j=1}^{m} \frac{\left[\operatorname{Ln}^{3+}\right]_{\text {meas }, i} K_{S, j}}{\left[\operatorname{Ln}^{3+}\right]_{\text {meas }, i} K_{S, j}+\left[H^{+}\right]_{\text {meas }, i}} \cdot\left[H A_{j}^{-}\right]
$$

The linear programming approach for multisite metal sorption solves a matrix equation, $\mathrm{b}$ $=A \cdot \mathrm{x}$, for $\mathrm{x}$. Here $A$ is an $n \times m$ matrix of $\alpha_{\mathrm{LnHA}, i j}$ entries as defined in Equations 5 and 6 . The $\mathrm{b}$ vector is a $n \times 1$ vector of calculated bound metal concentrations for each titrant addition, $\left[\mathrm{LnHA}^{2+}\right]_{\mathrm{T}, \mathrm{cal}, i}$, , as defined in Equation 6 . The $m \times 1$ vector $\mathrm{x}$ contains the adjustable parameters, $\left[\mathrm{HA}_{\mathrm{j}}^{-}\right]$, for each of the $m$ binding sites. Numerical difficulties exist in attempting to fit the model in Equation 6 because binding constants and site densities are correlated parameters. This problem is solved using a fixed interval grid of $\log K_{\mathrm{S}, \mathrm{j}}$ values and writing the problem in matrix form, as described by Martinez et al. [31]. In addition, the nature of the matrices as described above makes this an ill-posed problem, meaning that more than one error minimum can be found from optimization for $\mathrm{x}$ as a solution to the equation $\mathrm{b}=A \cdot \mathrm{x}$, unless additional assumptions are made about the nature of the solution [31].

Linear programming regression minimizes the number of binding sites and the absolute error, $e=\left|\left[\mathrm{LnHA}^{2+}\right]_{\mathrm{T}, \mathrm{cal}, i}-\left[\mathrm{LnHA}^{2+}\right]_{\mathrm{T}, i}\right|$, using a simplex method [29]. This approach finds one 
global minimum for the error function, which emphasizes zero as a possible solution and avoids convergence problems such as those found in FITEQL [30, 31]. LPM optimizes parameters such as total binding site concentrations. Each site density, [HA], is assigned a positive value where zero is a possible result. This generates a $\log K_{\mathrm{S}, j}$ spectrum where discrete metal-binding sites are determined by the number of $\log K_{\mathrm{S}, j}$ values, which have a corresponding nonzero metal-bindingsite density. When $\left[\mathrm{HA}_{\mathrm{j}}^{-}\right]$values are added, their sum should approximate the total available ligand concentration on the sorbent surface, $[\mathrm{HA}]_{\mathrm{T}}$, for a maximum experimental $\mathrm{pH}$ value.

In our simulations, the binding of the Ln first hydrolysis product to HA was not considered. This choice is supported by the fact that (i) all but two data points (among 28) have $\mathrm{pH}<7$; yet, it is well established that the proportion of Ln-OH complexes and thus Ln-OH-HA complexes may become important only for water samples having $\mathrm{pH}>8$ [17, 33]; (ii) even for alkaline waters, recent model calculations show that Ln speciation can be reasonably well captured by only considering $\mathrm{Ln}^{3+}$ complexation with HA [34].

\section{RESULTS AND DISCUSSION}

Tables 1 to 3 summarize LPM optimization results of $\log K_{\mathrm{S}, \mathrm{j}}$, $\left[\mathrm{HA}_{\mathrm{j}}\right]$ and $[\mathrm{HA}]_{\mathrm{T}}$ as defined by Equations 2 and 4 respectively for experimental $\left[\mathrm{Ln}^{3+}\right]$ sorption by three different initial HA concentrations of $5 \mathrm{mg} \mathrm{L}^{-1}$ to $20 \mathrm{mg} \mathrm{L}^{-1}$, in the $\mathrm{pH}$ range of 2-10. Tables 1 and 2 indicate the $\log K_{\mathrm{S}, \mathrm{j}}$ and [HA $]_{\mathrm{T}}$ values for all Ln elements at the full range of HA concentrations, while Table 3 shows $\left[\mathrm{HA}_{\mathrm{j}}^{-}\right.$] for 2 sites (i.e., $\mathrm{j}=2$ ) at $5 \mathrm{mg} \mathrm{L}^{-1} \mathrm{HA}$. LPM optimization of Equation 6 finds an optimal solution set of binding site concentrations, $\left[\mathrm{HA}_{\mathrm{j}}^{-}\right]$, which are assigned to the corresponding $\log K_{\mathrm{S}, \mathrm{j}}$ on fixed interval grid. This procedure generates a discrete spectrum and by approximating the ideal condition e $=\left|\left[\mathrm{LnHA}^{2+}\right]_{\mathrm{T}, \text { calc,i }}\left[\mathrm{LnHA}^{2+}\right]_{\mathrm{T}, \mathrm{j}}\right|=0 . \mathrm{LPM}$ optimization should generate a unique binding site density corresponding to a single $\log K_{\mathrm{S}, \mathrm{j}}$ on the grid. However, 
double peaks resulted for particular sites $\mathrm{j}$ (data not shown), because the true $\log K_{\mathrm{S}, \mathrm{j}}$ of the sample falls at an intermediate position between two adjacent $\log K_{\mathrm{S}, \mathrm{j}}$ on the grid [31]. Each doublet was converted to a single peak by averaging the two $\log K_{\mathrm{S}, \mathrm{j}}$ values and computing the weighted average of $\left[\mathrm{HA}_{\mathrm{j}}^{-}\right]$. The averaged values, along with existing single peaks, in replicate spectra were used to calculate overall average $\log K_{\mathrm{S}, \mathrm{j}}$ and $\left[\mathrm{HA}_{\mathrm{j}}^{-}\right]$values (log $K_{\mathrm{S}, \mathrm{j}(\mathrm{avg})}$ and [HA ${ }^{-}$ $\mathrm{j}]_{(\mathrm{avg})}$ ).

The $\log K_{\mathrm{S} \text {,(avg) }}$ and binding site densities obtained for the three humic acid concentrations are reported in Tables 1 and 2, for the 14 analyzed Ln elements respectively. The

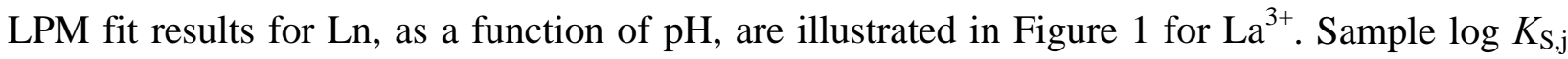
values for $\mathrm{La}^{3+}$ are $2.65 \pm 0.21$ and 7 , and $3.00 \pm 0.14$ and $3.85 \pm 0.07$ for $[\mathrm{HA}]_{\mathrm{T}}=5 \mathrm{mg} \mathrm{L}^{-1}, 10$ mg $\mathrm{L}^{-1}$ and $20 \mathrm{mg} \mathrm{L}^{-1}$, respectively. The main characteristics of the LnHA experiments, reproduced by LPM, are a low proportion of LnHA complexes at relatively low pH and a marked increase of this proportion with increasing $\mathrm{pH}$. The $\log K_{\mathrm{S}, \mathrm{j}}$ values increase with HA concentration of experimental solutions (e.g., for La from 2.65 to 3.85 for HA concentrations of $5 \mathrm{mg} \mathrm{L}^{-1}$ and $20 \mathrm{mg} \mathrm{L}^{-1}$, respectively). Moreover, $\log K_{\mathrm{S}, \mathrm{j}}$ values increase from La (2.65) to $\operatorname{Pr}$ (2.75), then decrease from $\mathrm{Eu}(2.70)$ to $\mathrm{Lu}$ (2.60) for HA concentrations of $5 \mathrm{mg} \mathrm{L}^{-1}$. This feature is further marked for a higher HA concentration (i.e., $20 \mathrm{mg} \mathrm{L}^{-1}$ ) where $\log K_{\mathrm{S}, \mathrm{j}}$ values increase from $\mathrm{La} \mathrm{(3.85)} \mathrm{to} \mathrm{Eu}(4.15)$ and then decrease from Gd (4.06) to Lu (3.95). It follows a $\log K_{\mathrm{S}, \mathrm{j}}$ pattern showing a middle rare earth elements (MREE) downward concavity (Figure 2). As already proposed by Pourret et al. [27], literature compilation of REE-organic ligand constants as plotted against $\mathrm{Gd} / \mathrm{Yb}$ ratio (Figure 3) evidenced that new calculated $\log K_{\mathrm{S}, \mathrm{j}}$ values are in the field of natural carboxylic acids and phenolic acids. As the objective of this study was not to document fractionation among Ln series, differences in between Sonke and Salters [25] and Pourret et al. [27] were not discussed (for that see discussions in [27, 28]). 
As evidenced in Table 1, two log $K_{\mathrm{S}, \mathrm{j}}$ values are proposed by LPM for HA concentration of $5 \mathrm{mg} \mathrm{L}{ }^{-1}$. This feature reflects the heterogeneity of HA binding sites which is known to be composed from carboxylic group varying from 3.2 to 4.8 meq $\mathrm{g}^{-1}$ and phenolic ones from 1.4 meq $\mathrm{g}^{-1}$ to 3.4 meq g$^{-1}$ [35]. This latter characteristic is only evidenced by the first experimental condition as it is the only one that spans up to a $\mathrm{pH}$ of 10 , and thus only the conditions considering $\mathrm{pH}$ greater than 7, can allow development of binding sites at alkaline $\mathrm{pH}$ (i.e., phenolic or polycarboxylic ones). Indeed, the contribution of the second site by just doubling the concentration of HA from $5 \mathrm{mg} \mathrm{L}^{-1}$ to $10 \mathrm{mg} \mathrm{L}^{-1}$, should still be expected at $10 \mathrm{mg} \mathrm{L}^{-1}$ and $20 \mathrm{mg}$ $\mathrm{L}^{-1}$, since the contribution of the second site may reached up to $30 \%$ (i.e., from Er to $\mathrm{Lu}$ ) at $5 \mathrm{mg}$ $\mathrm{L}^{-1}$. However, analytical window does not allow this latter feature to express at both HA concentration of $10 \mathrm{mg} \mathrm{L}^{-1}$ and $20 \mathrm{mg} \mathrm{L}^{-1}$ (i.e., $\mathrm{pH}$ does not exceed $\mathrm{pH}$ values of 7.26 and 6.77, respectively) as phenolic functional groups mostly expressed from $\mathrm{pH} 8$ to 10 [35]. This latter feature is also a verification of the results of Štamberg et al. [36] who previously studied $\mathrm{Eu}^{3+}$ complexation to Aldrich HA and found that phenolic groups only occur, in Ln complexation, at alkaline pH after neutralization of carboxylic groups. The corresponding total site densities $\left([\mathrm{HA}]_{\mathrm{T}}\right)$ are $2.89 \times 10^{-8} \mathrm{~mol} \mathrm{~g}^{-1}, 5.05 \times 10^{-8} \mathrm{~mol} \mathrm{~g}^{-1}$, and $5.02 \times 10^{-8} \mathrm{~mol} \mathrm{~g}^{-1}$ of $\mathrm{HA}$, for $5 \mathrm{mg} \mathrm{L}^{-1}$, $10 \mathrm{mg} \mathrm{L}^{-1}$ and $20 \mathrm{mg} \mathrm{L}^{-1}$ of HA, respectively for La (Table 2). These latter total site densities only correspond to ca. $1 \%$ of the available sites on HA surfaces. Among these sites, as displayed in Table 3 for HA concentration of $5 \mathrm{mg} \mathrm{L}^{-1}$, two types of sites may be considered. Weaker sites (i.e., sites with a mean $\log K_{\mathrm{S}, \mathrm{j}}$ value of 2.65) are predominant and represent 67 to $94 \%$ of the active binding sites whereas stronger sites (i.e., sites with a mean $\log K_{\mathrm{S}, \mathrm{j}}$ value of 7.00 ) only represent 6 to 33\% of the active binding sites. The corresponding site densities were $2.71 \pm 0.57$ x $10^{-8}$ and $0.58 \pm 0.32 \times 10^{-8}$ moles of $\mathrm{Ln}^{3+} / \mathrm{mg}$ of HA. As already observed, sites densities decrease with increasing $\log K_{\mathrm{S}, \mathrm{j}}$ values [21]. 
Even if this study only considered monodentate sites, an interesting feature would be evidenced by the three HA concentrations. The binding of Ln by several separate complexing sites on HA may occur (i.e., carboxylic and phenolic binding sites) resulting in the fact that metal binding will depend upon the total HA concentration. In other words, two monodentate binding sites would result in lower total site densities available to complex Ln, as compared to a unique binding site. This lower total site density observed at the HA concentration of $5 \mathrm{mg} \mathrm{L}^{-1}$, for all 14 Ln elements, indicates a direct correlation between the amount of Ln sorbed on the external surface microenvironment of HA which would increase with increasing HA concentration. This result confirms the results explained earlier, where the concentration of complexed metal is proportional to the concentration of added HA [37]. Oppositely, for the same conformation (i.e., one single monodentate site at a HA concentration of $10 \mathrm{mg} \mathrm{L}^{-1}$ and $20 \mathrm{mg} \mathrm{L}^{-1}$ ) there is no concentration dependence. Albeit not considered in this study, multidentate binding may also become increasingly important with increasing $\mathrm{pH}$.

As evidenced by Table 3 and Figure 4, site density distribution varies in between Ln. Sites 1 are more predominant (i.e., represent $>80-90 \%$ of the binding sites) for the MREE (i.e., from Nd to Dy) whereas for La or Lu they only represent $77 \%$ or $67 \%$ of the available binding sites. Complementary, "sites 2” in Table 3 are more present for binding La and Lu as regards to MREE (i.e., 23\% or 33\% compared to $<10-20 \%$ ). This heterogeneity in the distribution of site types may thus reflect the competition among Ln elements which is responsible of the fractionation in between the Ln series. It must be noted that Ce does not follow this general trend which may be ascribed to its redox behaviour. $\log K_{\mathrm{S}, \mathrm{j}}$ values for the Ln series are maximum for $\mathrm{Sm}^{3+}$. Binding site densities display the same feature. It may be the result of the Ln coordination number change in the Ln complexes in solution from 9 to 8, which usually occurs in the $\mathrm{Eu}^{3+}$ to $\mathrm{Gd}^{3+}$ range. The water molecules about the inner $\mathrm{Ln}$ sphere is 9 from $\mathrm{La}^{3+}$ to $\mathrm{Nd}^{3+}$, and 8 from $\mathrm{Tb}^{3+}$ to $\mathrm{Lu}^{3+}$ [38]. From a thermodynamical point of view the free energy of the Ln coordination 
number change in the $\mathrm{Eu}^{3+}$ to $\mathrm{Gd}^{3+}$ range as a result of the sudden change of the coordination polyhedrons type. Indeed, Choppin and Peterman [39] pointed out that Eu-acetate complexes occur as inner sphere and as acetate represents a model molecule of simple carboxylic sites on complex organic matter such as HA [9], such a coordination number change must be expected in the $\mathrm{Eu}^{3+}$ to $\mathrm{Gd}^{3+}$ range. These processes are induced by variations of inter electronic repulsive potentials due to progressive filling of $4 f$ orbital during structural changes that especially involve inner coordination sphere of each Ln caused by equilibrium ligand exchange reaction (e.g., organic phase-aqueous phase equilibrium). Indeed, when processes involve Ln adsorption (or surface complexation) with an inner sphere mechanism, non-CHARAC effect may take place. The complexation behaviour of Ln does not thus exclusively depend on its ionic charge and radius, but is additionally controlled by its electron configuration and by the type of complexing ligand, since this latter two determine the character of the chemical bonding. Hence, aqueous systems are characterized by non-CHARAC trace element behaviour [3], and electron structure must be considered as an additional parameter. However, such a behaviour need to be further explored and refined.

As already discussed by Pourret et al. [27] and Stern et al. [28] observed differences between experiments presented by Takahashi et al. [40], Yamamoto et al. [41, 42], Sonke and Salters [25], and both of these studies (i.e., [27], [28]) strongly suggest the heterogeneity of the complexing sites in HS: high concentration of weak carboxylic sites and low concentrations of strong phenolic sites [35]. The weak sites determine the behaviour of humic complexation at high metal loading, whereas the strong sites determine the complexation strength of humic substances at trace metal concentrations [27], [28], even when their concentration is only in the range of a few percent of the weak sites (i.e., 10 to $22 \%$; [35]). HS/Ln ratios considered in this study are between 5 and 20, whereas in Yamamoto et al. [41, 42] experiments they are close to 80, in Sonke and Salters [25] and Stern et al. [28] between 500 and 700, and in Takahashi et al. [40] as 
high as 100,000 . At lower loading, stronger sites are favored whereas at higher loadings, weaker sites are involved in the complexation. Moreover, phenolic sites are predominant at alkaline $\mathrm{pH}$ whereas carboxylic are dominant binding sites at acidic $\mathrm{pH}$. Indeed, the $\mathrm{pH}$ range in this study spans from 2 to 10 with an analytical window in the 2-6 range, whereas in Yamamoto et al. [41, 42] experimental pH varies between 4 and 5.5 and, in Sonke and Salters [25] and Stern et al. [28] it varies between 6 and 10. The present study sheds more light on the process dealing with Ln loading by HA and needs to be extended to other HS by modelling existing data [25], [28] with LPM to generalize this feature. In addition, all results, whether those of our study and Pourret et al. [27] or those of Sonke and Salters [26] and Stern et al. [28], suggest that the multi functionality of the organic matter surface site should be taken into account differently in speciation studies and calculation codes. Indeed, whether Model V and VI, each of the models considered the existence of two groups of surface sites that can form monodentate, bidentate (e.g., as in Model V; [43]) and tridentate (e.g., as in Model VI; [14]) complexes. However, their abundance and complexation constants are linked one to another by mathematical expressions and as regards to Ln behaviour (i.e., fractionation among Ln series as regards to binding site affinities), and may be refined considering the results obtained using LPM.

\section{SUMMARY}

Linear programming modelling was able to determine differences in Ln speciation as a function of increasing humic acid concentration. At low concentrations of dissolved organic matter two Ln binding sites were found, whereas one site is obtained at higher amounts. Lanthanide binding occurs mainly at weak sites (i.e., ca. 80\%; attributed to carboxylic groups) and secondly at strong sites (i.e., ca. 20\%; attributed to phenolic moieties). However, heterogeneity in the distribution of the binding sites among $\mathrm{Ln}$ is evidenced, which could explain Ln fractionation patterns. Moreover, this study has been able to quantify LnHA interactions, 
including the determination of metal binding constants and site concentrations without the need for initial knowledge of these parameters, indicating the usefulness of the linear programming modelling approach to solving surface metal complexation in the presence of complex organic surfaces. Previous models including FITEQL have produced incomparable results emphasizing the use of LPM as a tool for quantification of metal-ligand interactions as previously suggested $[29,31]$.

\section{Acknowledgements}

We thank the Biogeochemical Group from Géosciences Rennes for useful discussions when we were both in Rennes, and the Geologists Rock! Group in Beauvais when finalizing this project. Two anonymous reviewers are acknowledged for useful comments and Catherine Wilson and Genevieve Green are acknowledged for editorial handling. 


\section{REFERENCES}

[1] P. Henderson, Rare earth element geochemistry, Elsevier, Amsterdam, 1984.

[2] R. D. Shannon, Acta Crystallogr. A32 (1976) 751-767.

[3] M. Bau, Contrib. Mineral. Petrol. 123 (1996) 323-333.

[4] S. A. Wood, Chem. Geol. 82 (1990) 159-186.

[5] K. B. Krauskopf, Chem. Geol. 55 (1986) 323-335.

[6] R. H. Byrne, B. Li, Geochim. Cosmochim. Acta 59 (1995) 4575-4589.

[7] A. Dia, G. Gruau, G. Olivié-Lauquet, C. Riou, J. Molénat, P. Curmi, Geochim. Cosmochim. Acta 64 (2000) 4131-4151.

[8] B. Dupré, J. Viers, J.-L. Dandurand, M. Polvé, P. Bénézeth, P. Vervier, J.-J. Braun, Chem. Geol. 160 (1999) 63-80.

[9] S. A. Wood, Eng. Geol. 34 (1993) 229-259.

[10] J. Viers, B. Dupré, M. Polvé, J. Schott, J.-L. Dandurand, J. J. Braun, Chem. Geol. 140 (1997) 181-206.

[11] E. M. Thurman, Organic Geochemistry of Natural Waters, Nijhoff/Junk, Dordrechtthe, 1985.

[12] M. Plaschke, J. Rothe, M. A. Denecke, T. Fanghänel, J. Electron. Spectrosc. Relat. Phenom. 135 (2004) 53-62.

[13] A. L. Herbelin, J. C. Westall, FITEQL, A computer program for determination of chemical equilibrium constants from experimental data, Report 99-01, Department of Chemistry, Oregon State University, Corvallis, 1999.

[14] E. Tipping, Aquat. Geochem. 4 (1998) 3-48.

[15] D. G. Kinniburgh, W. H. van Riemsdijk, L. K. Koopal, M. Borkovec, M. F. Benedetti, M. J. Avena, Colloid Surface A 151 (1999) 147-166. 
[16] V. Moulin, J. Tits, C. Moulin, P. Decambox, P. Mauchien, de Ruty O., Radiochim. Acta 58-59 (1992) 121-128.

[17] A. Maes, J. De Brabandere, A. Cremers, Radiochim. Acta 44-45 (1988) 51-57.

[18] C. Franz, G. Herrmann, N. Trautmann, Radiochim. Acta 77 (1997) 177-181.

[19] G. Bidoglio, I. Grenthe, P. Qi, P. Robouch, N. Omenetto, Talanta 38 (1991) 999-1008.

[20] J. R. Lead, J. Hamilton-Taylor, A. Peters, S. Reiner, E. Tipping, Anal. Chim. Acta 369 (1998) 171-180.

[21] A. Dierckx, A. Maes, J. Vancluysen, Radiochim. Acta 66-67 (1994) 149-156.

[22] J. Tang, K. H. Johannesson, Geochim. Cosmochim. Acta 67 (2003) 2321-2339.

[23] O. Pourret, M. Davranche, G. Gruau, A. Dia, Geochim. Cosmochim. Acta 71 (2007) 2718-2735.

[24] E. Tipping, M. A. Hurley, Geochim. Cosmochim. Acta 56 (1992) 3627-3641.

[25] J. E. Sonke, V. J. M. Salters, Geochim. Cosmochim. Acta 70 (2006) 1495-1506.

[26] J. E. Sonke, Environ. Sci. Technol. 40 (2006) 7481-7487.

[27] O. Pourret, M. Davranche, G. Gruau, A. Dia, Chem. Geol. 243 (2007) 128-141.

[28] J. C. Stern, J. E. Sonke, V. J. M. Salters, Chem. Geol. 246 (2007) 170-180.

[29] P. Brassard, J. R. Kramer, P. V. Collins, Environ. Sci. Technol. 24 (1990) 195-201.

[30] R. E. Martinez, F. G. Ferris, J. Colloid Interface Sci. 243 (2001) 73-80.

[31] R. E. Martinez, K. Pedersen, F. G. Ferris, J. Colloid Interface Sci. 275 (2004) 82-89.

[32] P. Zhou, H. Yan, B. Gu, Chemosphere 58 (2005) 1327-1337.

[33] Y. Takahashi, Y. Minai, S. Ambe, Y. Makide, F. Ambe, Geochim. Cosmochim. Acta 63 (1999) 815-836.

[34] O. Pourret, M. Davranche, G. Gruau, A. Dia, J. Colloid Interface Sci. 305 (2007) 25-31.

[35] J. D. Ritchie, E. M. Perdue, Geochim. Cosmochim. Acta 67 (2003) 85-96.

[36] K. Štamberg, P. Beneš, J. Mizera, J. Dolanský, D. Vopálka, K. Chalupská, J. Radioan. Nucl. Ch. 258 (2003) 329-345. 
[37] E. Tipping, Cation binding by humic substances, University Press, Cambridge, 2002.

[38] D. G. Brookins, in: P. H. Ribbe, (Ed.) The Mineralogical Society of America: Washington, 1989, pp 201-225.

[39] G. R. Choppin, D. R. Peterman, Coordin. Chem. Rev. 174 (1998) 283-299.

[40] Y. Takahashi, Y. Minai, S. Ambe, Y. Makide, F. Ambe, T. Tominaga, Sci. Total Environ. 198 (1997) 61-71.

[41] Y. Yamamoto, Y. Takahashi, H. Shimizu, Chem. Lett. 34 (2005) 880-881.

[42] Y. Yamamoto, Y. Takahashi, H. Shimizu, Geochim. Cosmochim. Acta Goldschmidt Conference Abstracts (2006) doi:10.1016/j.gca.2006.06.1587.

[43] E. Tipping, Comput. Geosci. 20 (1994) 973-1023. 


\section{TABLES AND FIGURES CAPTIONS}

Table 1. Log $K_{\mathrm{s}, \mathrm{j}}$ values.

Table 2. Total site density (in mol of $\mathrm{Ln}^{3+} / \mathrm{mg}$ of $\mathrm{HA}$ ).

Table 3. Site density for both sites at a HA concentration of $5 \mathrm{mg} \mathrm{L}^{-1}$ (in mol of $\mathrm{Ln}^{3+} / \mathrm{mg}$ of HA).

Figure 1. Binding of (a) La, (b) Eu and (c) Lu to HA for various HA concentrations (i.e., 5 mg L'

1, $10 \mathrm{mg} \mathrm{L}^{-1}$ and $20 \mathrm{mg} \mathrm{L}^{-1}$ ) as a function of $\mathrm{pH}$. Points correspond to experimental data [22] whereas solid lines correspond to LPM best fits for which the absolute error $e$ is minimal.

Figure 2. $\log K_{\mathrm{s}, \mathrm{j}}$ patterns for the $14 \mathrm{Ln}$.

Figure 3. Literature compilation of REE-organic ligand constants (recalculated at $I=0.1 \mathrm{~mol} \mathrm{~L}^{-1}$ when necessary; [6, 9]). black triangles: amino-carboxylic acids; white squares: iminoacetic acids; black circles: phenolic acids; grey circles: carboxylic acids; white circles: natural carboxylic acids: dark grey circles: humic substances, Aldrich Humic Acid (AHA), Suwannee River Fulvic Acid (SRFA), Suwannee River Humic Acid (SRHA), Leonardite Humic Acid (LHA), Suwannee River Natural Organic Matter (SRNOM) and Summit hill Soil Humic Acid

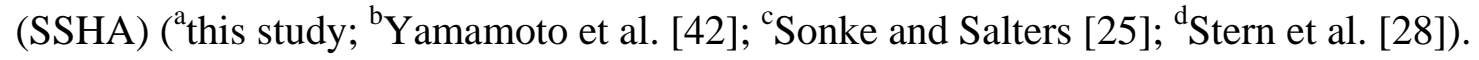

Figure 4. Site density distribution (in mol of $\mathrm{Ln}^{3+} / \mathrm{mg}$ of HA) for the $14 \mathrm{Ln}$ (data are from Table $3)$. 


\begin{tabular}{lcccc}
\hline [HA] mg L & \multicolumn{2}{c}{$\mathbf{5}$} & $\mathbf{1 0}$ & $\mathbf{2 0}$ \\
\hline $\mathrm{La}$ & $2.65 \pm 0.21$ & 7.00 & $3.00 \pm 0.14$ & $3.85 \pm 0.07$ \\
$\mathrm{Ce}$ & $2.60 \pm 0.21$ & 7.00 & $3.25 \pm 0.07$ & $3.95 \pm 0.07$ \\
$\mathrm{Pr}$ & $2.75 \pm 0.21$ & 7.00 & $3.15 \pm 0.21$ & $4.05 \pm 0.07$ \\
$\mathrm{Nd}$ & $2.60 \pm 0.21$ & 7.00 & $3.40 \pm 0.14$ & $4.10 \pm 0.07$ \\
$\mathrm{Sm}$ & $2.70 \pm 0.21$ & 7.00 & $3.35 \pm 0.07$ & $4.15 \pm 0.07$ \\
$\mathrm{Eu}$ & $2.70 \pm 0.21$ & 7.00 & $3.35 \pm 0.07$ & $4.15 \pm 0.07$ \\
$\mathrm{Gd}$ & $2.60 \pm 0.21$ & 7.00 & $3.25 \pm 0.07$ & $4.05 \pm 0.07$ \\
$\mathrm{~Tb}$ & $2.60 \pm 0.21$ & 7.00 & $3.25 \pm 0.07$ & $3.95 \pm 0.07$ \\
$\mathrm{Dy}$ & $2.60 \pm 0.21$ & 7.00 & $3.10 \pm 0.14$ & $3.95 \pm 0.07$ \\
$\mathrm{Ho}$ & $2.65 \pm 0.21$ & 7.00 & $3.10 \pm 0.14$ & $3.95 \pm 0.07$ \\
$\mathrm{Er}$ & $2.65 \pm 0.21$ & 7.00 & $3.15 \pm 0.07$ & $3.95 \pm 0.07$ \\
$\mathrm{Tm}$ & $2.65 \pm 0.21$ & 7.00 & $3.15 \pm 0.07$ & $3.95 \pm 0.07$ \\
$\mathrm{Yb}$ & $2.65 \pm 0.21$ & 7.00 & $3.10 \pm 0.14$ & $3.95 \pm 0.07$ \\
$\mathrm{Lu}$ & $2.65 \pm 0.21$ & 7.00 & $3.15 \pm 0.07$ & $3.95 \pm 0.07$ \\
\hline
\end{tabular}

Table 1. 


\begin{tabular}{lrrr}
\hline [HA] mg L & $\mathbf{- 1}$ & $\mathbf{5}$ & $\mathbf{1 0}$ \\
\hline $\mathrm{La}$ & $2.89 \times 10^{-8}$ & $5.05 \times 10^{-8}$ & $5.02 \times 10^{-8}$ \\
$\mathrm{Ce}$ & $3.31 \times 10^{-8}$ & $5.00 \times 10^{-8}$ & $5.02 \times 10^{-8}$ \\
$\mathrm{Pr}$ & $3.21 \times 10^{-8}$ & $4.99 \times 10^{-8}$ & $5.01 \times 10^{-8}$ \\
$\mathrm{Nd}$ & $3.65 \times 10^{-8}$ & $4.97 \times 10^{-8}$ & $5.00 \times 10^{-8}$ \\
$\mathrm{Sm}$ & $3.75 \times 10^{-8}$ & $4.98 \times 10^{-8}$ & $5.00 \times 10^{-8}$ \\
$\mathrm{Eu}$ & $3.65 \times 10^{-8}$ & $4.98 \times 10^{-8}$ & $5.01 \times 10^{-8}$ \\
$\mathrm{Gd}$ & $3.50 \times 10^{-8}$ & $4.99 \times 10^{-8}$ & $5.00 \times 10^{-8}$ \\
$\mathrm{~Tb}$ & $3.44 \times 10^{-8}$ & $4.98 \times 10^{-8}$ & $5.01 \times 10^{-8}$ \\
$\mathrm{Dy}$ & $3.30 \times 10^{-8}$ & $4.98 \times 10^{-8}$ & $4.98 \times 10^{-8}$ \\
$\mathrm{Ho}$ & $3.20 \times 10^{-8}$ & $5.00 \times 10^{-8}$ & $5.02 \times 10^{-8}$ \\
$\mathrm{Er}$ & $3.04 \times 10^{-8}$ & $4.99 \times 10^{-8}$ & $5.01 \times 10^{-8}$ \\
$\mathrm{Tm}$ & $3.03 \times 10^{-8}$ & $4.98 \times 10^{-8}$ & $5.01 \times 10^{-8}$ \\
$\mathrm{Yb}$ & $3.01 \times 10^{-8}$ & $4.98 \times 10^{-8}$ & $5.00 \times 10^{-8}$ \\
$\mathrm{Lu}$ & $3.00 \times 10^{-8}$ & $4.98 \times 10^{-8}$ & $4.98 \times 10^{-8}$ \\
\hline
\end{tabular}

Table 2. 


\begin{tabular}{lll}
\hline & Site 1 & Site 2 \\
\hline $\mathrm{La}$ & $2.22 \times 10^{-8}$ & $0.67 \times 10^{-8}$ \\
$\mathrm{Ce}$ & $3.05 \times 10^{-8}$ & $0.26 \times 10^{-8}$ \\
$\mathrm{Pr}$ & $2.56 \times 10^{-8}$ & $0.65 \times 10^{-8}$ \\
$\mathrm{Nd}$ & $3.30 \times 10^{-8}$ & $0.35 \times 10^{-8}$ \\
$\mathrm{Sm}$ & $3.38 \times 10^{-8}$ & $0.37 \times 10^{-8}$ \\
$\mathrm{Eu}$ & $3.32 \times 10^{-8}$ & $0.33 \times 10^{-8}$ \\
$\mathrm{Gd}$ & $3.25 \times 10^{-8}$ & $0.25 \times 10^{-8}$ \\
$\mathrm{~Tb}$ & $3.20 \times 10^{-8}$ & $0.24 \times 10^{-8}$ \\
$\mathrm{Dy}$ & $3.10 \times 10^{-8}$ & $0.20 \times 10^{-8}$ \\
$\mathrm{Ho}$ & $2.40 \times 10^{-8}$ & $0.80 \times 10^{-8}$ \\
$\mathrm{Er}$ & $2.04 \times 10^{-8}$ & $1.00 \times 10^{-8}$ \\
$\mathrm{Tm}$ & $2.05 \times 10^{-8}$ & $0.98 \times 10^{-8}$ \\
$\mathrm{Yb}$ & $2.04 \times 10^{-8}$ & $0.97 \times 10^{-8}$ \\
$\mathrm{Lu}$ & $2.00 \times 10^{-8}$ & $1.00 \times 10^{-8}$ \\
\hline
\end{tabular}

Table 3. 

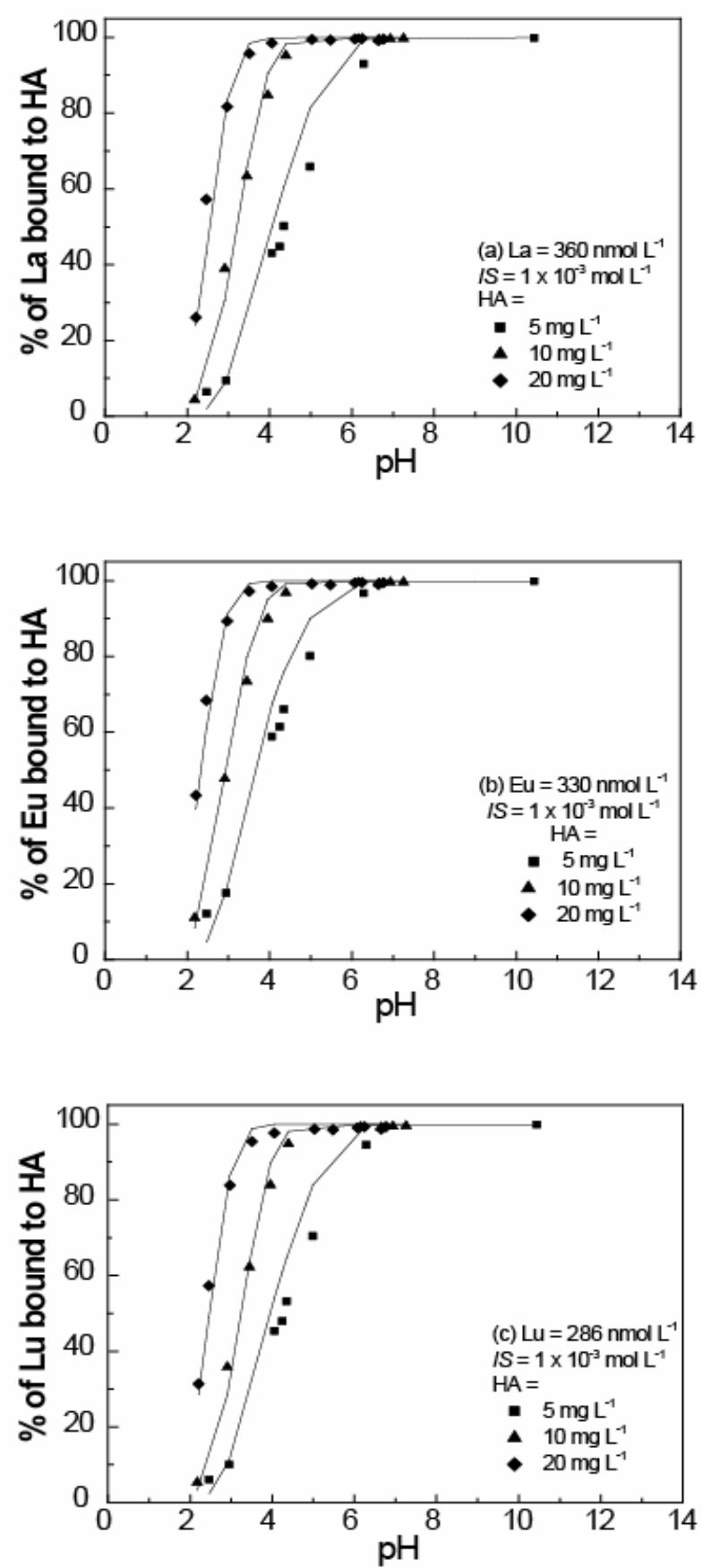

Figure 1. 


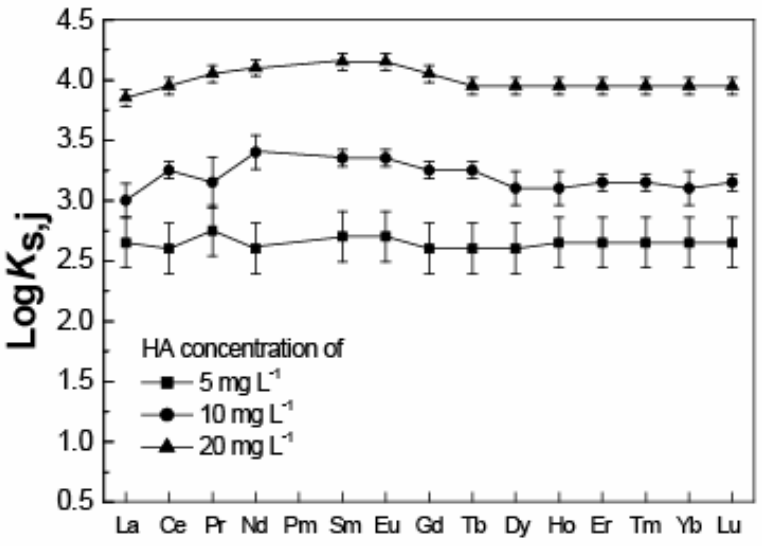

Figure 2. 


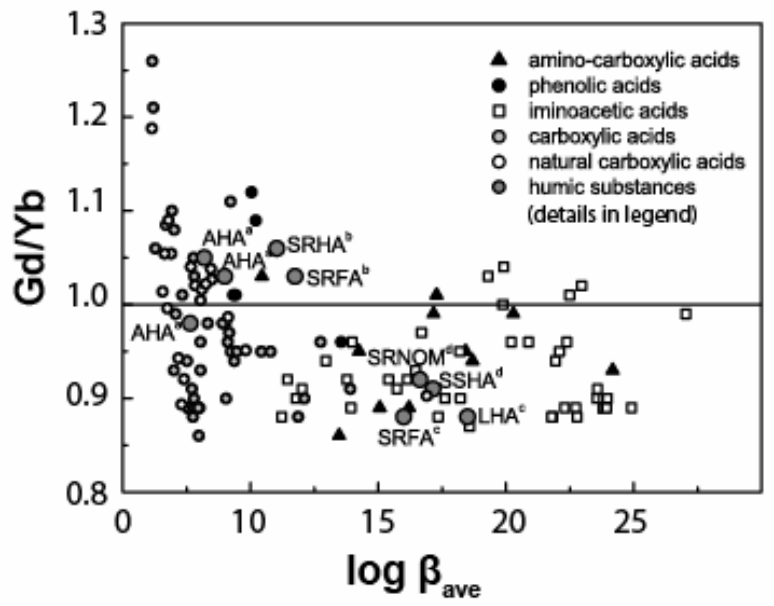

Figure 3. 


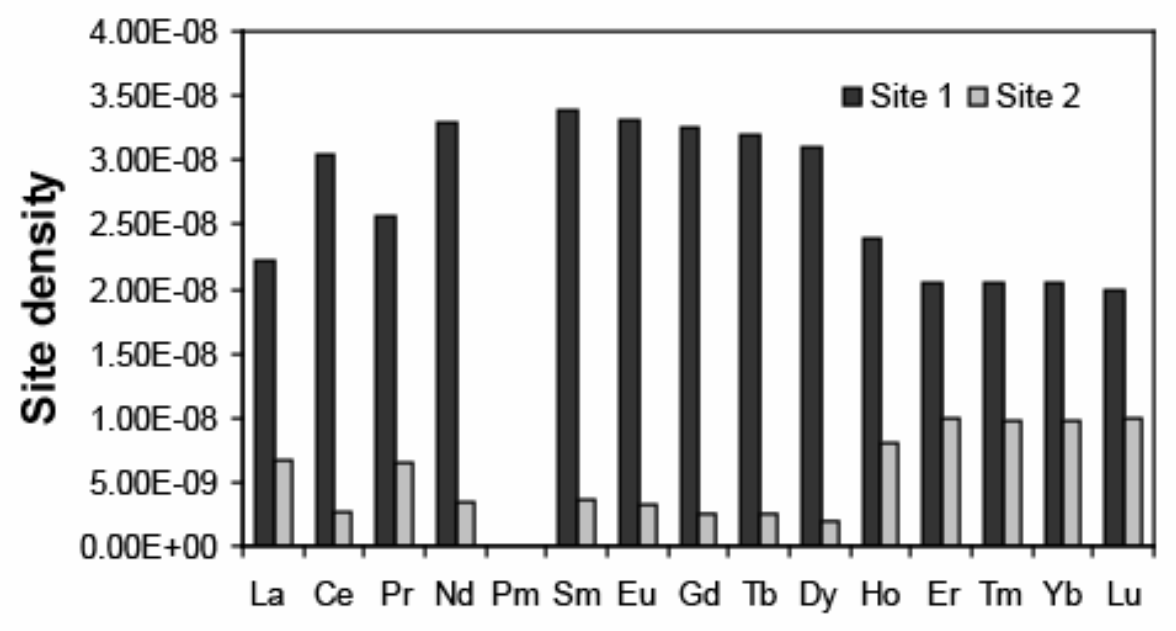

Figure 4. 